\title{
Effect of Atmospheric-Pressure Plasmas on Drug Resistant Melanoma: The Challenges of Translating In vitro Outcomes into Animal Models
}

\author{
Musarat Ishaq, ${ }^{\mathrm{a}, \mathrm{b}, \star}$ Anthony Rowe ${ }^{\mathrm{c}}$ Kateryna Bazaka, ${ }^{\mathrm{d}, \mathrm{e}}$ Mark Krockenberger, ${ }^{\mathrm{f}}$ \\ Margaret D. M. Evans, ${ }^{a}$ \& Kostya (Ken) Ostrikov ${ }^{\mathrm{d}, \mathrm{e}}$ \\ ${ }^{a}$ Commonwealth Scientific and Industrial Research Organisation (CSIRO) Manufacturing Flagship, \\ North Ryde, New South Wales, Australia; ${ }^{b}$ Peter MacCallum Cancer Institute, East Melbourne, \\ Victoria, Australia; 'CSIRO Food and Nutrition Flagship, North Ryde, New South Wales, Australia; \\ ${ }^{d}$ CSIRO-QUT Joint Sustainable Materials and Devices Laboratory, Commonwealth Scientific and

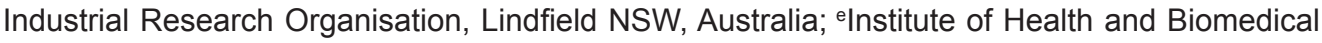 \\ Innovation, School of Chemistry, Physics, and Mechanical Engineering, Queensland University \\ of Technology, Brisbane, Queensland, Australia; 'Department of Veterinary Pathology, Faculty \\ Veterinary Science, University of Sydney, Sydney, Australia \\ *Address all correspondence to: Musarat Ishaq, Peter MacCallum Cancer Institute, East Melbourne, VIC 3002, Australia, \\ E-mail: ishaqmusarat@gmail.com
}

\begin{abstract}
Atmospheric-pressure plasmas (APs) have been identified as a promising cancer therapy that is able to preferentially kill neoplastic cells through apoptosis. In vitro studies suggest that AP-generated reactive oxygen species (ROS) are the principal triggers of apoptosis-related signaling cascades via oxidative stress and direct interference with DNA, proteins, and other cellular components. The results of this study corroborate an ROS-mediated mechanism of cancer cell death, with apoptosis in AP-treated Mel-007 melanoma cells inhibited by pretreatment of cells with the ROS scavenger N-acetylcysteine or the caspase inhibitor zVAD-fmk. In an effort to compare apoptosis mechanisms and evaluate the in vitro-in vivo correlation for AP-induced apoptosis, Mel-007 cells were injected subcutaneously into mice to form solid tumors and were treated with AP. Histological assessment of tumors from control and AP-treated animals showed no significant difference in tumor volume, mitotic rate, or percentage of necrosis or multinucleate cells. These results vary from those of other studies of AP treatment of xenograft tumors in murine models, in which a decrease in tumor size and tumor volume were observed. These findings focus our attention on challenges associated with translating the in vitro results to corresponding in vivo outcomes, and highlight concerns about the applicability of mechanisms established in vitro to an intrinsically dynamic in vivo environment.
\end{abstract}

KEY WORDS: apoptosis, cell culture, melanoma, plasma treatment, reactive oxygen species

\section{INTRODUCTION}

Melanoma is the main cause of skin cancer mortality, and Australia has the highest incidence of melanoma in the world. ${ }^{1}$ Approximately $50 \%$ of melanomas harbor activating (V600E) mutations in the serine-threonine protein kinase B-RAF (BRAF $\left.{ }^{\mathrm{V} 600 \mathrm{E}}\right)$. The $B R A F$ gene provides instructions for making a protein involved in transmitting chemical signals from outside a cell to a cell's nucleus as part of the RAS/mitogenactivated protein kinase signaling pathway that regulates cell proliferation, migration, 
and apoptosis. Mutations cause the BRAF protein to be constitutively expressed, even in the absence of chemical signals, which may contribute to the growth of cancers by allowing abnormal cells to grow and divide uncontrollably. The most effective chemotherapeutic treatments for BRAF mutant melanomas are BRAF inhibitors (e.g., dabrafenib, trametinib, vemurafenib), but resistance invariably develops through BRAF truncation, upstream mutation in NRAS, or downstream mutations in MEK. ${ }^{2,3}$ Similar to $B R A F$ mutations, mutations in the NRAS gene lead to a continuously active NRAS protein and consequential abnormal cell proliferation and differentiation. Activated NRAS mutations are detected in 15-20\% of melanomas. ${ }^{4}$ Mutations in MEK genes are found in about $8 \%$ of melanomas and result in the production of the abnormally active proteins MEK1 and MEK2, which function as part of the RAS/mitogen-activated protein kinase signaling pathway; these mutations lead to faster cell division and may contribute to tumor formation. ${ }^{5}$

An alternative therapeutic approach to the treatment of melanoma is the tumor necrosis factor-related apoptosis-inducing ligand, which specifically induces apoptosis in melanoma; unfortunately, resistance to this ligand may also develop ${ }^{6,7}$ Indeed, resistance to chemotherapeutic drugs is considered the greatest obstacle to the successful clinical management of cancer patients and the main contributor to the failure of chemotherapy. ${ }^{8}$ An anticancer treatment should ideally be cytotoxic to cancer cells, have minimal effects on normal cells, and reduce the possibility of resistance. Atmospheric-pressure plasma (AP) has the potential to fill this niche as an anticancer therapy because it can selectively induce apoptosis in neoplastic cells. ${ }^{9} 10$ Plasmas used for cancer treatment operate near room temperature in air. They create a mixture of charged and neutral reactive oxygen species (ROS) and reactive nitrogen species (RNS) that may be involved in apoptosis, with specificity for cancer cells. ${ }^{9-12}$ Since oncogenesis involves the dysregulation of apoptosis, targeting apoptosis pathways is an attractive therapeutic approach. ${ }^{13-15}$

The effect of AP treatment on the signaling and checkpoint pathways that govern the cell cycle of a wide range of cancer cells has been investigated by many groups, leading to the identification of several molecular mechanisms that potentially drive selective apoptosis in cancer cells. ${ }^{10,16-22}$ These researchers generally agree that the specific effects of plasmas depend on the plasma dosage (which is broadly defined by the proximity of plasmas to the treated object and the treatment duration) and the plasma chemical composition, which in turn is determined by the gas composition and the mode and energy used to produce these plasmas. ${ }^{23}$ The respective contributions of specific plasma effects-such as ion and neutral species, energetic electrons, photons, electric and magnetic fields, charging of surfaces, current flows, and others - to apoptotic cancer cell death remain a subject of active debate. ${ }^{10,24,25}$ Given the reports of selective apoptosis of cancer cells by plasma-activated media in vitro and in vivo, in the absence of direct contact with the plasma, ${ }^{26-30}$ many researchers are of the view that AP-generated ROS and RNS are the primary drivers of plasma-induced apoptosis. However, other investigators failed to obtain a significant apoptotic effect using plasma-activated media alone, ${ }^{31}$ warranting further investigations into plasma-induced apoptosis specifically, 
and into the nature of plasma-cell/tissue interactions more broadly. Indeed, in addition to the induction of apoptosis, in vitro plasma treatments have been shown to promote cancer cell detachment and loss, and impede cell growth, migration and invasiveness, and clonogenicity, leading to cell cycle arrest and cell senescence, mitochondrial dysfunction, downregulation of integrins, DNA damage, and modulation of the ATM/ p53 pathway. ${ }^{20,22,25,32-35}$

Translation of the in vitro results to corresponding in vivo outcomes presents an equally significant challenge because of the highly complex and dynamic nature of the latter. Quantitative and qualitative in vitro to in vivo extrapolations to predict the efficacy and evaluate the potential side effects of any type of cancer therapy is not trivial; concerns are often raised about the applicability of in vitro-derived chemicalspecific parameters and mechanisms established in vitro to model intrinsically dynamic and complex in vivo processes. Direct AP treatment or exposure to AP-treated media in vivo have been shown to inhibit tumor growth, hinder cell proliferation, and induce cell death, leading to an overall reduction in tumor size. ${ }^{30}$ In this study AP generated with the kINPen Plasma MED (KPM) ${ }^{36,37}$ was used to explore the extent to which in vitro treatment parameters can be effectively transferred into the in vivo environment, and whether the mechanisms involved in the regulation of cellular responses to atmosphericpressure plasma treatment in vitro would be observed in vivo.

\section{METHODS}

\section{A. Atmospheric-Pressure Plasma Jet Device}

The KPM (INP Greifswald/Neoplas Tools GmbH, Greifswald, Germany), a European Conformity-certified medical device that meets EU safety, health, and environmental regulations, generates a cold atmospheric-pressure plasma jet. The apparatus consists of a handheld unit (length, $170 \mathrm{~mm}$; diameter, $20 \mathrm{~mm}$ ), a power supply, and a gas supply unit (Fig. 1A). The handheld unit includes a pin-type electrode (diameter, $1 \mathrm{~mm}$ ) located in the center of a quartz capillary (inner diameter, $1.6 \mathrm{~mm}$ ) and a grounded electrode surrounding the dielectric capillary. A high-frequency voltage $(1.1 \mathrm{MHz})$ is coupled to the internal electrode. The device is operated in continuous mode. A plasma plume is generated in the pen and extends to the surrounding air outside the nozzle, and the discharge effluent is directed toward the sample. Argon is used as a working gas at a flow rate of 1-2 standard $\mathrm{L} /$ minute.

The parameters of plasmas generated by KPM are well described in the literature. ${ }^{12,38}$ A systematic investigation of KPM-generated plasma parameters by Weltmann et al..$^{38}$ showed that at an argon gas flow rate of 1 standard L/minute and a distance of $5 \mathrm{~mm}$, the plasma temperature is within the acceptable range. The same study estimated that at this distance and a maximum input power of $6 \mathrm{~W}$, the maximum recorded irradiance in the 260- to 360-nm ultraviolet range is approximately $5 \mathrm{~W} / \mathrm{cm}^{2} \cdot{ }^{38}$ Fourier transform infrared analysis of biologically and chemically active species by various researchers showed the absorption features of $\mathrm{CO}_{2}, \mathrm{CO}$, nitric oxide (NO), $\mathrm{NO}_{2}, \mathrm{~N}_{2} \mathrm{O}, \mathrm{HNO}_{2}$, and $\mathrm{HNO}_{3}$, 
whereas $\mathrm{OH}$ and $\mathrm{O}_{3}$ species, which exist in the small volume of the active plasma, were not detected because of their high reactivity. ${ }^{39-41}$ Spatial mapping of the $\mathrm{O}_{3}$ concentration in the KPM plasma plume by Kelly et al. ${ }^{42}$ showed peak values of $238 \mathrm{ppb}$ within the vicinity of the nozzle $(<25 \mathrm{~mm})$, with a radius of $\sim 5 \mathrm{~mm}$. The diffusion of ambient air species, such as molecular oxygen and nitrogen, into the effluent of plasma produced by KPM have been discussed by Reuter et al. ${ }^{43}$

For in vitro experiments, cells were treated with a KPM plume for 5, 10, 15, 30, and 60 seconds. For in vivo experiments, solid subcutaneous tumors were treated with a KPM plume for 8 minutes/day for 7 consecutive days. The KPM plume was positioned $5 \mathrm{~mm}$ from the skin (Fig. 1B).

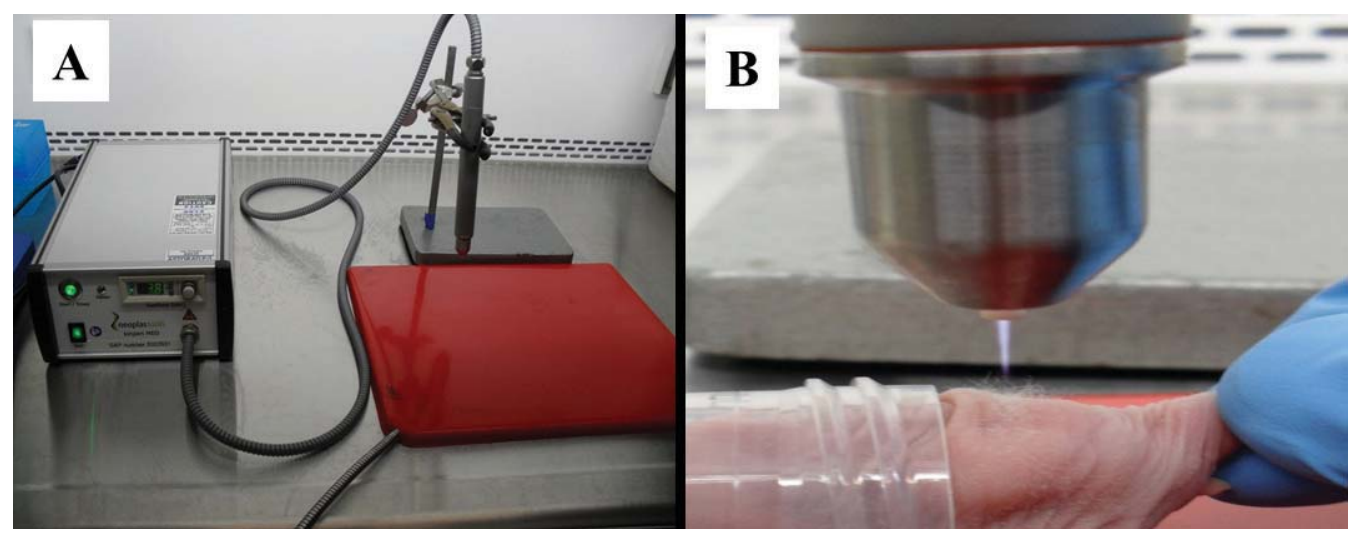

FIG. 1: (A) kINPen Plasma MED (KPM) atmospheric-pressure plasma device. (B) Treatment of a tumor-bearing mouse with KPM.

\section{B. Cell Culture and Reagents}

The human melanoma cell lines Mel-RM, Mel-007, and Mel-JD were a gift from Peter Hersey (Melanoma Institute, University of Sydney, Sydney, Australia) and were maintained in Dulbecco's modified Eagle medium (Invitrogen) plus 10\% fetal bovine serum. The caspase inhibitor ZVAD-fmk (G7231) and N-acetylcysteine (NAC) (a ROS scavenger; A0737) were purchased from Sigma-Aldrich (St. Louis, MO).

\section{Cell Proliferation and Caspase 3/7 Apoptosis Assays}

All cells were seeded overnight in 96-well plates at a concentration of $2 \times 10^{4}$ cells/well, treated with KPM for the indicated time periods, and incubated for 18-24 hours. Cell viability was measured using the CellTiter 96 Aqueous Non-Radioactive Cell Proliferation (MTS) Assay (G5421; Promega, Madison, WI) following the manufacturer's protocol. In some experiments the caspase inhibitor zVAD-FMK $(50 \mu \mathrm{mol} / \mathrm{L})$ or NAC $(3 \mathrm{mmol} / \mathrm{L})$ was added 1-2 hours before KPM treatment. Assays were performed in triplicate. For the 
apoptosis assay, cells were seeded in 96-well plates at a concentration of $2 \times 10^{4}$ cells/well, incubated for 24 hours, and then treated with KPM for the time periods indicated. Four to 8 hours after KPM treatment, caspase 3/7 activity was quantified by adding Caspase Glo 3/7 reagent (G8091; Promega). In some experiments the caspase inhibitor zVAD-FMK $(50 \mu \mathrm{mol} / \mathrm{L})$ or NAC $(3 \mathrm{mmol} / \mathrm{L})$ was added $1-2$ hours before KPM treatment. Triplicate samples were run in standard 96-well plates to quantify the apoptotic response. Luminescence values were then determined using a LUMIstar Omega plate reader.

\section{Animal Studies}

The use of animals in these experiments was approved by the Commonwealth Scientific and Industrial Research Organisation North Ryde Animal Ethics Committee. Sixweek-old BALB/c-Fox1nu/Ausb(BALB/c nude) mice $(n=23)$ were purchased from Australian BioResources Ltd (Moss Vale, NSW, Australia) and used for 3 experiments. These mice are immunodeficient and were selected to allow the growth of human melanoma cells into tumors; they have the added benefit that they do not need to be shaved or depilated to apply the plasma treatment and evaluate the growth of the subcutaneous tumor. Mice were allowed to acclimatize for 1 week before the experiments. There were 3 experimental lineages (described below) with predetermined end points. Tumors were collected postmortem for histopathology, and these were fixed in $4 \%$ neutral buffered formalin and embedded in paraffin. Sections of paraffin-embedded tissue were stained with hematoxylin and eosin, then viewed using a transmitted light microscope and scored by a registered veterinary pathologist (Veterinary Pathology Diagnostic Services, University of Sydney).

Experiment $1(\mathrm{n}=3)$ tested the effect of KPM on normal mouse skin (no tumors were induced). A plume of KPM was held $5 \mathrm{~mm}$ above the sacral dorsal midline of each mouse for 5 minutes. Mice were killed 0, 24, and 48 hours after treatment. Treated and untreated skin was removed and prepared for histopathology.

Experiment $2(n=6)$ tested the optimal concentration of Mel-007 cells needed to form a tumor in mice (no KPM treatment was applied). Pairs of mice were subcutaneously injected with either $1 \times 10^{5}, 1 \times 10^{6}$, or $1 \times 10^{7}$ cells in the left flank while under isoflurane general anaesthesia. In each case, $200 \mu \mathrm{L}$ of cells was mixed with $200 \mu \mathrm{L}$ Matrigel (BD Matrigel Basement Membrane Matrix, catalog no. 354234; BD Biosciences) for a total injection volume of $400 \mu \mathrm{L}$. Tumors were measured with digital calipers and volumes (V) (in millimeters cubed) were calculated according to the formula:

$$
V=\frac{\text { lenghh } \times \text { width } 2}{2},
$$

where length is the longest axis of the tumor. Tumors were excised at day 28 and prepared for histopathology.

Experiment $3(n=14)$ tested the impact of KPM treatment on tumors induced in mice using Mel-007 cells. Twelve mice were subcutaneously injected in the left flank

Volume 6, Issue 1, 2016 
with $1 \times 10^{7}$ cells in a total injection volume of $200 \mu \mathrm{L}(100 \mu \mathrm{L}$ cells $+100 \mu \mathrm{L}$ Matrigel $)$ while under isoflurane general anaesthesia. Two control mice were injected with $100 \mu \mathrm{L}$ phosphate-buffered saline (PBS) $+100 \mu \mathrm{L}$ Matrigel only (no cells). Tumors were allowed to establish for 7 days because this was the time required for the injected cells to adhere and grow into tumors and for tumors to develop vasculature. Then, six mice were treated with KPM for 8 minutes/day for 7 days. The treatment duration was inferred from prior in vitro experiments where desired in vitro activity, specifically significant apoptotic efficacy, was observed for 5- to 20-minute treatments without deleterious effects to healthy cells. The treatment protocol was similar to that used by Daeschlein et al. ${ }^{44}$ for the treatment of subcutaneous melanoma tumors, where tumors were treated through the intact skin with a different version of the KPM device for 5 minutes daily for 5 days. The plasma plume was positioned $5 \mathrm{~mm}$ from the skin. A study of the luminous plasma plume produced by the KPM device showed the plasma expanding from the nozzle and reaching/maintaining a maximum length of about 4.5-6 $\mathrm{mm}$ (up to $7 \mathrm{~mm}$ ) until the voltage is terminated..$^{45}$ The other 8 mice were controls ( 6 with tumors and 2 with Matrigel/PBS alone) and received no KPM treatment. All mice were killed on day 24 after tumor inoculation, at which point tumors were removed and prepared for histopathology.

\section{RESULTS AND DISC USSION}

Malignant melanoma is resistant to drug therapy, ${ }^{2,3}$ and its incidence is steadily increasing at a rate of 2-5\% per year. ${ }^{46}$ In Australia, between 2006 and 2010, melanoma accounted for $14 \%$ and $23 \%$ of all cancers diagnosed among 15 - to 19 - and 20 - to 24 -year-olds. ${ }^{47}$ Because of its superficial location, melanoma is a good candidate for direct AP treatment, and such possibility has been explored by several research groups..$^{26,27,46,48}$ The outcomes of these studies and the cell death mechanisms proposed varied with the plasma device used and the treatment protocol, suggesting alterations to the cell cycle, apoptosis, and necrosis. ${ }^{49}$ However, the nature of AP selectivity and the specific mechanisms by which AP preferentially induces cell death in tumor cells remain to be fully explored. One potential reason for this is the variability of the experimental procedure (plasma device, cell line, treatment duration). Another significant aspect lies in the nature of most studies, wherein the focus is generally placed on individual effects related to a particular application of interest rather than an attempt to correlate cell responses and intracellular dynamics. ${ }^{50}$ Further complexities arise from in vivo studies in which the model is both highly complex and dynamic, with a high degree of inherent variability. In practical terms this means that process parameters and mechanisms derived from in vitro experimentation have limited relevance and/or require significant optimization to be accurately applied in vivo.

In this article we identified an example where in vitro-derived parameters did not translate into expected in vivo outcomes, bringing to the attention of the community the potential challenges associated with in vitro-to-in vivo translation. This is particularly relevant to the field of plasma medicine now, as it is transitioning from cell culturebased to tissue and animal models. First, we examine further the mechanism of cancer 
cell death in vitro, and then we investigate the extent to which the killing effect, as well as the toxicity of the treatment to healthy tissues, can be replicated in vivo.

\section{A. KPM Induces Apoptosis in Melanoma Cells In vitro}

Direct and indirect exposure to plasma-generated effects has been shown to effectively and selectively kill different melanoma cancer cell lines, and a number of mechanisms have been proposed. Exposure of premetastatic and metastatic melanoma cell lines to plasma generated using surface micro-discharge resulted in irreversible cell inactivation, DNA damage, induction of sub- $\mathrm{G}_{1}$ phase and proapoptotic events such as p53 and Rad17 phosphorylation, activation of caspase 3 , and release of cytochrome c. ${ }^{46}$ While not able to induce apoptosis, shorter durations of the same treatment led to senescence in melanoma cells. Apoptosis was also identified as the key cancer cell death mechanism for melanoma cells treated with plasmas generated using other types of devices. ${ }^{48,51,52}$ In another study the adhesion molecules of G361 melanoma cells were significantly affected by the exposure to a radiofrequency microplasma jet (e.g., with filamentous actin changing its morphology), leading to the significant detachment of cells from the collagen-coated surfaces and a lack of directionality in the attached cells. ${ }^{53}$ The expression of integrin $\alpha_{2}$, integrin $\alpha_{4}$, and FAK was also inhibited as a result of the plasma treatment. These proteins play notable role in malignant transformation and the attainment of metastatic phenotypes. ${ }^{54,55}$ Morphological changes and subsequent cell death were also observed in 1205Lu melanoma cells. ${ }^{56}$

Our previous studies using a custom-made plasma device showed that APs induced apoptosis in cancer cells by activating caspases via JNK/p 38 kinases, inducing expression of the proapoptotic phorbol-12-myristate-13-acetate-induced protein (NOXA), and expression of the tumor suppressor protein TP73..$^{26,27,48}$ In this study we tested the effect of a different device, the KPM atmospheric-pressure plasma jet, on melanoma cancer cell lines. Three melanoma cell lines (Mel-RM, Mel-007, and Mel-JD) were sensitive to the cytotoxic effects of KPM (Fig. 2). Mel-007 cells also showed a significant increase in caspase $3 / 7$ activity when treated with KPM, but this activity was inhibited by pretreating cells with the ROS inhibitor NAC or the caspase inhibitor zVAD (Fig. 3). These results suggest that the apoptotic pathway induced by KPM is regulated by caspases $3 / 7$ and is dependent on KPM-produced ROS. The susceptibility of neoplastic cells to AP and ROS may be a function of a dysregulated cell cycle and a higher cellular metabolic rate. Hence the effects of ROS could be amplified in neoplastic cells compared with those under normal homeostatic control mechanisms.

\section{B. In vivo Effects of KPM on Melanoma}

Unlike the ideal in vitro (static) conditions in which plasma anticancer efficacy is routinely demonstrated, in vivo exposure conditions are systemically interactive and dynamic. Consequently, it is often challenging to predict the required conditions that would generate chemical concentrations and induce biological processes in the target cancer tissue

Volume 6, Issue 1, 2016 


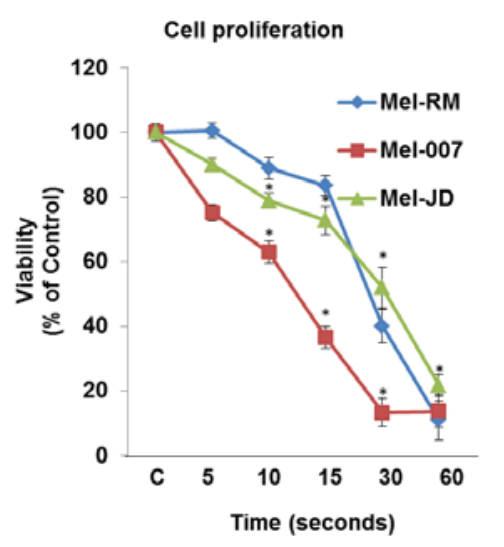

FIG. 2: kINPen Plasma MED (KPM) decreases cancer cell survival. Melanoma (Mel-RM, Mel-007, and Mel-JD) cells were treated with KPM for 5, 10, 15, 30, and 60 seconds. After 24 hours of treatment, cell viability was assessed by the MTS/PMS cell proliferation assay, which measures the activity of live cells. Cell viability is expressed as a percentage of that in control (C) untreated cells.

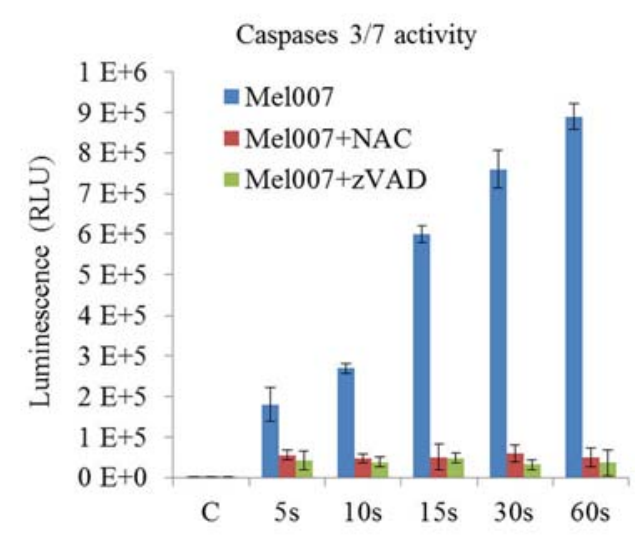

FIG. 3: Caspase 3/7 activity in kINPen Plasma MED (KPM)-treated cells. Mel-007 cells were pretreated with the reactive oxygen species scavenger N-acetylcysteine (NAC) or the caspase inhibitor zVAD for 1-2 hours and treated with KPM for 5, 10, 15, 30, and 60 seconds. After 24 hours of treatment with KPM, the Caspase-Glo 3/7 apoptosis assay was used to determine apoptosis by recording luminescence. Luminescence (as relative light units [RLUs]) is proportional to the relative caspase activity of plasmas for the induction of apoptosis. C, control.

(where cancer cells present as a solid tumor) that are equivalent to those at which effects were observed in an in vitro environment (where tumor cells are growing in a monolayer). As such, extensive optimization is often necessary to translate the technology from an in vitro to an in vivo setting. Equally difficult is the prediction of in vivo outcomes based on mechanisms derived from in vitro studies and/or modeling efforts. This information transfer is further complicated by the selection of an animal model and the type of tumor cells used to induce a solid tumor, as well as inconsistencies in the methodology and approach used for in vitro studies, which is certainly the case for plasma medicine.

In our first experiment we confirmed that treatment with KPM had no deleterious effect on the skin of the mice used for all experiments. Histopathology of skin samples showed no difference between KPM-treated and control skin specimens. Each specimen showed an epidermis that was 3-4 cells thick, with generalized epidermal hyperkeratosis and a moderate stratum granulosum. The superficial dermis consisted of relatively dense connective tissue with a moderate cellularity above the normal subcutis and cutaneous musculature.

In our second experiment we sought to confirm that Mel-007 cells, which have not previously been used in animal studies, would form a tumor at the injection site. Eight 
days after inoculation, tumors (125 and $150 \mathrm{~mm}^{3}$ ) were present in the pair of mice injected with $1 \times 10^{7}$ cells. No tumors were observable in the other pairs of mice at day 8 . By day 28 , these tumors were 250 and $400 \mathrm{~mm}^{3}$, respectively. At this point mice were killed and tumors were harvested for analysis by histopathology. The appearance of the tumors was consistent with amelanotic malignant melanoma, demonstrating successful tumor cell implantation. Tumors of similar sizes were present in both of the mice injected with $1 \times 10^{6}$ cells, but only one of the mice injected with $1 \times 10^{5}$ cells.

Among the numerous species generated during the course of plasma treatment, NO (in RNS) and hydrogen peroxide $\left(\mathrm{H}_{2} \mathrm{O}_{2}\right)$ and hydroxyl free radicals (in ROS) are considered as important players in inducing cancer cell apoptosis in the literature..$^{57-59}$ Other biologically relevant species include $\mathrm{O}_{2}^{-},{ }^{1} \mathrm{O}_{2}, \mathrm{NO}_{2}^{-}, \mathrm{NO}_{3}^{-}, \mathrm{ONOO}^{-}$, and, more recently, $\mathrm{Cl}_{2}^{-}$and $\mathrm{ClO}^{-}$that arise from the reaction between oxygen atoms and $\mathrm{Cl}^{-}$in a solution ${ }^{60}$; however, the specific contributions of these species to the apoptotic effect are yet to be elucidated. Furthermore, since many of the reported apoptosis studies were drawn from the experiments involving direct application of plasmas on cancer cells, it is not yet clear whether these species play an equally important role in inducing apoptosis in cells treated with plasma-activated media. ${ }^{61}$ Yan et al. ${ }^{61}$ recently investigated the accumulation of RNS and ROS species in plasma-activated media, demonstrating that, with a half-life of only a few microseconds, $\mathrm{OH}$ radicals are too reactive to penetrate deep into the media (farther than perhaps several hundred micrometers from the liquid surface). Reactive $\mathrm{Cl}_{2}^{-}$and $\mathrm{ClO}^{-}$species are also relatively short-lived under normal cellular conditions, and as such quickly transform into a less reactive form. On the other hand, $\mathrm{H}_{2} \mathrm{O}_{2}$ (which to a large degree is formed from $\mathrm{OH}$ ) and $\mathrm{NO}$ are sufficiently stable to penetrate the media and subsequently induce the biological effects in media-treated cells. ${ }^{40}$ The interactions of plasma-generated species with components of biological fluid and cellular membranes also influence the kinetics of consumption of plasma-generated ROS; for example, alkyl-peroxide radicals (ROO·) can be generated as a result of interactions between plasma-generated ROS and serum components. ${ }^{62}$

In addition to species stability in media, the speed at which they can diffuse across the cellular membrane plays an important role in determining the amount of intracellular ROS. A degree of similarity between water and $\mathrm{H}_{2} \mathrm{O}_{2}$ enables the latter to be transported across the cellular membrane by aquaporins (e.g., AQP8) ${ }^{62}$ According to Yan et al., ${ }^{61}$ the uptake - and hence the efficacy - $\mathrm{of}_{2} \mathrm{O}_{2}$ in inducing apoptosis depends on the properties of the cell membrane and hence varies among different types of cancer cells. Within a cell, in the presence of $\mathrm{Fe}^{2+}, \mathrm{H}_{2} \mathrm{O}_{2}$ can further form reactive $\mathrm{OH}$ (via the Fenton reaction), which in turn can damage DNA and other intracellular molecules. It is important to note that although $\mathrm{H}_{2} \mathrm{O}_{2}$ may indeed be the dominant species involved in inducing apoptosis in the cancer cells subjected to plasma-treated media ${ }^{61}$ it is by no means the only one. Indeed, an equivalent solution of $\mathrm{H}_{2} \mathrm{O}_{2}$ does not induce the same apoptotic effect as plasma-treated media, suggesting an important role for other plasma-generated species. NO has been shown to affect mitochondrial function through interaction with components of the electron-transport chain, and as such it not only regulates cell respiration but also

Volume 6, Issue 1, 2016 
increases the generation of ROS by mitochondria, activating mechanisms of cell survival or death. ${ }^{63} \mathrm{NO}$ can further increase the toxicity of $\mathrm{H}_{2} \mathrm{O}_{2}$ by inhibiting $\mathrm{H}_{2} \mathrm{O}_{2}$ degradation ${ }^{64}$ and inactivating glutathione peroxidase ${ }^{65}$ and other antioxidant molecules.

In the third experiment we sought to test the efficacy of KPM treatment on tumors of melanoma origin induced in mice. Tumors from control and KPM-treated animals were assessed by histopathology, and no significant difference was found in tumor volume, mitotic rate per 10 high-powered fields, percentage of necrosis or multinucleate cells per 10 high-powered fields at day 24 after tumour inoculation (Table 1). Seven of 12 tumors were $10-30 \%$ necrotic, with no observed difference between the treated and untreated groups (Table 2). No tissue change at the injection site was observed postmortem in the 2 control mice injected with Matrigel/PBS. Using a smaller volume of injection for experiment $3(200 \mu \mathrm{L})$ resulted in a more localized injection and more uniform tumors than in experiment $2(400 \mu \mathrm{L})$.

Together, these experiments showed that Mel-007 cells form a localized, vascularized melanoma when injected subcutaneously into nude mice (Fig. 4). Injecting $1 \times 10^{7}$ cells mixed with Matrigel (1:1) in a total injection volume of $200 \mu \mathrm{L}$ was optimal for the concentrations tested. The KPM treatment regime used had no deleterious effect on the skin of the nude mice used in our study. We noted with interest that KPM treatment of the tumors in our study did not reduce tumor volume, and minimal evidence of necrosis was observed when analyzed by histopathology. This was unexpected given published reports by other research groups, where significant differences were observed between tumors harvested from control and plasma-treated mice. For example, in a similar study using melanoma implantation into the flank of C57BL/6N mice, treatment of the tumor

TABLE 1: Characteristics of Tumors from Control and kINPen Plasma MED-Treated Animals as Assessed by Histopathology

\begin{tabular}{lccc}
\hline & Volume $\left(\mathbf{m m}^{3}\right)$ & $\begin{array}{c}\text { Mitotic Rate } \\
(\text { per 10 } \mathbf{~ h p f s})\end{array}$ & $\begin{array}{c}\text { Multinucleate Cells } \\
(\text { per 10 hpfs })\end{array}$ \\
\hline Control $(\mathbf{n}=\mathbf{6})$ & $149.3 \pm 39.6$ & $25.2 \pm 15.8$ & $3.5 \pm 1.5$ \\
Treatment $(\mathbf{n}=\mathbf{6})$ & $166.1 \pm 53.7$ & $26.8 \pm 14.4$ & $3.8 \pm 2.1$ \\
\hline
\end{tabular}

Data are the sample means \pm standard deviations. hpf, high-powered field.

TABLE 2: Contingency Table for Necrosis Scoring of Histology Samples

\begin{tabular}{lccccc}
\hline & \multicolumn{5}{c}{ Necrosis (\%) } \\
& $0-10$ & $10-20$ & $20-30$ & $30-40$ & $40-50$ \\
\hline Control $(\mathbf{n}=\mathbf{6})$ & 1 & 2 & 2 & 0 & 1 \\
Treatment $(\mathbf{n}=\mathbf{6})$ & 1 & 2 & 1 & 1 & 1 \\
Total & 2 & 4 & 3 & 1 & 2 \\
\hline
\end{tabular}

There is one count for the whole tumor from each animal. 


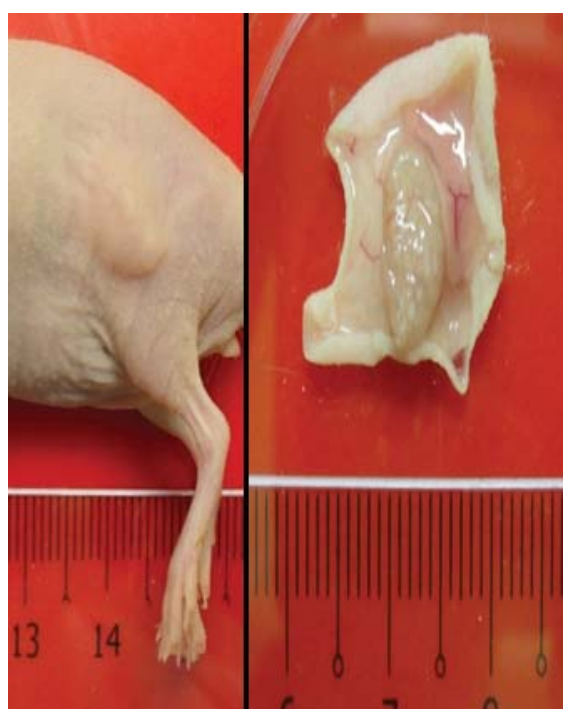

FIG. 4: A tumor-bearing mouse killed on day 24 after tumor inoculation (left), with the excised tumor (right).

with plasmas generated by either an atmospheric-pressure plasma jet or dielectric barrier discharge resulted in a significant delay in tumor growth acceleration. ${ }^{44}$ A significant reduction in tumor volume and weight $-16 \mathrm{~mm}^{3}$ and $42 \mathrm{mg}$ for treated mice compared with $80 \mathrm{~mm}^{3}$ and $96 \mathrm{mg}$ for control mice, respectively_was observed for plasma-treated pancreatic tumors in a murine model; this was largely attributed to a high rate of ROS generation in the vicinity of the cells and ensuing apoptosis. ${ }^{17}$ The observed accumulation of cells in the $\mathrm{S}$ phase of the cell cycle indicated an arrest of tumor proliferation, whereas a 3-fold increase in caspase-3-positive cells and their homogenous distribution in the treated tumors confirmed the induction of apoptosis in plasma-treated tumors. ${ }^{19}$ Reduced tumor volume positively contributed to the animals' life span, increasing it by $60 \%$ (from 9.5 to 15.0 days). ${ }^{18}$ Although none of the aforementioned in vivo studies reported any significant deleterious effects of plasma treatment on healthy tissues, the repeated long plasma treatment ( $20 \mathrm{~min}$./day) of U87-luc glioma tumors using pulsed dielectric barrier discharge with microsecond pulses resulted in an increase in the subcutaneous temperature and a cutaneous skin $\mathrm{pH}$ reduction during the treatment, as well as a superficial burn. ${ }^{66}$

It is possible the KPM plasma plume used in these experiments was too narrow to be effective. In the experiments by Keidar et al., ${ }^{10}$ the plasma treatment was applied when the tumor diameter was $<5 \mathrm{~mm}$, corresponding to a volume of $\sim 65 \mathrm{~mm}^{3}$, which is significantly smaller than that used in this study. Considering that the diameter of KPM plasma plume is $\sim 1 \mathrm{~mm}$, the plume may cover only a very limited surface of the tumor within the treatment time, especially in the case of larger tumors. It is also possible that the intensity of the electric and magnetic fields applied to generate plasma (and hence

Volume 6, Issue 1, 2016 
the plasma dosage) may have not been sufficient to induce the desired effect in vivo. ${ }^{18,66}$ Interestingly, with an initial melanoma tumor diameter of $\sim 8 \mathrm{~mm}$, Daeschlein et al. ${ }^{44}$ were able to attain some positive antitumor effects using a different version of kINPen; in their experiment, however, the device was brought into direct contact with the surface of the skin. It is also possible that the chemical composition of the generated plasma species differed between our experiment and those of others in which reductions in tumor size and volume were observed."

In addition to using a broader beam to cover the entire tumor, indirect treatments such as the injection of atmospheric gas plasma-treated tissue culture media into tumors may be more effective. The indirect application (by injection) of a plasmatreated medium into xenografted tumors of chronic paclitaxel- or cisplatin-resistant ovarian cancer cells in a mouse model resulted in an average inhibition of $66 \%(P<$ 0.05 ) and $52 \%$, respectively. ${ }^{30}$ The use of the ROS scavenger NAC counteracted the growth-inhibitory effects of plasma treatment, suggesting that, similar to our results for melanoma, ROS are the key contributors to plasma-induced apoptosis. It would be intuitive to expect direct plasma treatment to be even more effective because of the added contribution of, for example, an electric field and ultraviolet light. Alternatively, it is possible that, by treating media, a different range of biologically active, long-lived species may be generated (e.g., through chemical reactions between plasma-generated species and amino acids present in the media). This opens an interesting avenue for further research. ${ }^{67,68}$

Better therapeutic outcomes may be attained by first surgically excising the tumor, then using KPM treatment on the tissues in the wound bed to induce apoptosis in any residual cancer cells to potentially avoid tumor regrowth and metastasis. Bringing plasma-generated reactive species and plasma-induced effects (e.g., an electric field) in close proximity to cancer cells may augment the apoptotic effect. Furthermore, a study by Partecke et al. ${ }^{21}$ showed that apoptotic and necrotic effects were confined to the top layers of the treated tumor (depth of tissue penetration up to $60 \mu \mathrm{m}$ ), with cells below the top 5 layers of the tumor retaining their usual rate of proliferation. This may provide an explanation regarding the relatively insignificant effect of reported plasma treatments on survival rates. ${ }^{10,21,44,66}$ Following the same argument, injection of the plasma-activated media directly inside the tumor may reach the deepest layers of the tumor, ${ }^{30}$ and hence may be better suited to the treatment of larger tumors, where higher concentrations of reactive species may need to be delivered with minimal detriment to the surrounding healthy tissues. Removal of the solid tumor before treatment, or treatment of tumors while they are relatively small, may deliver a more permanent resolution of the tumor and positively contribute to patient survival rates.

Other strategies to improve the efficacy of atmospheric-pressure plasma treatment would involve optimization of the treatment protocol—such as specific gas composition and flow rates, treatment time and periodicity, distance between the plasma jet nozzle and the skin surface-as well as synergistic treatments involving anticancer drugs that are currently in use or being developed. ${ }^{69}$ 


\section{CONCLUSIONS}

APs may ultimately provide a specific cancer treatment that overcomes the development of resistance that occurs with many conventional chemotherapy protocols through the activation of apoptotic pathways in neoplastic cells. Although successful in monolayer cell culture experiments, further trials with AP are required to determine how to deliver an effective treatment through multiple layers of different tissues (e.g., skin, fat, and connective tissue) to all cells in the solid, 3-dimensional tumours that occur in vivo.

\section{ACKNOWEDGMENTS}

The authors thank Professor Peter Hersey from the University of Sydney for providing the melanoma cell lines. The authors also thank Penny Bean, Dr. Vijay Vaithilingam, Denise Lewy, and Sumeet Bal at Commonwealth Scientific and Industrial Research Organisation (CSIRO) for useful discussions and support for the experimental work and equipment. This study was supported by the CSIRO OCE postdoctoral fellowship program, the CSIRO Science Leadership program, the CSIRO Transformational Biology and Advanced Materials Transformational Capability Platforms, and the Australian Research Council (DE130101550).

\section{REFERENCES}

1. Wong CC, Liu W, Gies P, Nixon R. Think UV, not heat! Australas J Dermatol. 2015;56(4):275-8.

2. Chapman PB, Hauschild A, Robert C, Haanen JB, Ascierto P, Larkin J, Dummer R, Garbe C, Testori A, Maio M, Hogg D, Lorigan P, Lebbe C, Jouary T, Schadendorf D, Ribas A, O’Day SJ, Sosman JA, Kirkwood JM, Eggermont AMM, Dreno B, Nolop K, Li J, Nelson B, Hou J, Lee RJ, Flaherty KT, McArthur GA. Improved survival with vemurafenib in melanoma with braf v600e mutation. New Engl J Med. 2011;364(26):2507-16.

3. Flaherty KT, Robert C, Hersey P, Nathan P, Garbe C, Milhem M, Demidov LV, Hassel JC, Rutkowski P, Mohr P, Dummer R, Trefzer U, Larkin JMG, Utikal J, Dreno B, Nyakas M, Middleton MR, Becker JC, Casey M, Sherman LJ, Wu FS, Ouellet D, Martin A-M, Patel K, Schadendorf D. Improved survival with mek inhibition in braf-mutated melanoma. New Engl J Med. 2012;367(2):107-14.

4. Johnson DB, Lovly CM, Flavin M, Panageas KS, Ayers GD, Zhao Z, Iams WT, Colgan M, DeNoble S, Terry CR, Berry EG, Iafrate AJ, Sullivan RJ, Carvajal RD, Sosman JA. Impact of NRAS mutations for patients with advanced melanoma treated with immune therapies. Cancer Immunol Res. 2015;3(3):288-95.

5. Hocker TL, Singh MK, Tsao H. Melanoma genetics and therapeutic approaches in the 21st century: moving from the benchside to the bedside. J Invest Dermatol. 2008;128(11):2575-95.

6. Ashkenazi A, Holland P, Eckhardt SG. Ligand-based targeting of apoptosis in cancer: the potential of recombinant human apoptosis ligand 2/tumor necrosis factor-related apoptosis-inducing ligand (rhapo21/TRAIL). J Clin Oncol. 2008;26(21):3621-30.

7. Zhang XD, Zhang XY, Gray CP, Nguyen T, Hersey P. Tumor necrosis factor-related apoptosis-inducing ligand-induced apoptosis of human melanoma is regulated by smac/DIABLO release from mitochondria. Cancer Res. 2001;61(19):7339-48.

8. Kaelin WG Jr. Choosing anticancer drug targets in the postgenomic era. JJ Clin Invest. 1999;104(11):1503-6.

9. Graves D. The emerging role of reactive oxygen and nitrogen species in redox biology and some

Volume 6, Issue 1, 2016 
implications for plasma applications to medicine and biology. J Phys D Appl Phys. 2012;45(26): 263001.

10. Keidar M, Walk R, Shashurin A, Srinivasan P, Sandler A, Dasgupta S, Ravi R, Guerrero-Preston R, Trink B. Cold plasma selectivity and the possibility of a paradigm shift in cancer therapy. Brit J Cancer. 2011;105(9):1295-301.

11. Kim CH, Kwon S, Bahn JH, Lee K, Jun SI, Rack PD, Baek SJ. Effects of atmospheric nonthermal plasma on invasion of colorectal cancer cells. Appl Phys Lett. 2010;96(24):243701.

12. Weltmann KD, Kindel E, Woedtke TV, Hähnel M, Stieber M, Brandenburg R. Atmospheric-pressure plasma sources: prospective tools for plasma medicine. Pure Appl Chem. 2010;82(6):1223-37.

13. Berger MF, Levin JZ, Vijayendran K, Sivachenko A, Adiconis X, Maguire J, Johnson LA, Robinson J, Verhaak RG, Sougnez C, Onofrio RC, Ziaugra L, Cibulskis K, Laine E, Barretina J, Winckler W, Fisher DE, Getz G, Meyerson M, Jaffe DB, Gabriel SB, Lander ES, Dummer R, Gnirke A, Nusbaum C, Garraway LA. Integrative analysis of the melanoma transcriptome. Genome Res. 2010;20(4):413-27.

14. Hoek K, Rimm DL, Williams KR, Zhao H, Ariyan S, Lin A, Kluger HM, Berger AJ, Cheng E, Trombetta ES, Wu T, Niinobe M, Yoshikawa K, Hannigan GE, Halaban R. Expression profiling reveals novel pathways in the transformation of melanocytes to melanomas. Cancer Res. 2004;64(15):5270-82.

15. Chang JW, Kang SU, Shin YS, Kim KI, Seo SJ, Yang SS, Lee J-S, Moon E, Baek SJ, Lee K, Kim C-H. Non-thermal atmospheric pressure plasma induces apoptosis in oral cavity squamous cell carcinoma: Involvement of DNA-damage-triggering sub-g1 arrest via the atm/p53 pathway. Arch Biochem Biophys. 2014;545:133-40.

16. Keidar M, Shashurin A, Volotskova O, Ann Stepp M, Srinivasan P, Sandler A, Trink B. Cold atmospheric plasma in cancer therapy. Phys Plasmas. 2013;20(5):057101.

17. Brullé L, Vandamme M, Riès D, Martel E, Robert E, Lerondel S, Trichet V, Richard S, Pouvesle J-M, Le Pape A. Effects of a non thermal plasma treatment alone or in combination with gemcitabine in a mia paca2-luc orthotopic pancreatic carcinoma model. PLoS One. 2012;7(12):e52653.

18. Vandamme M, Robert E, Dozias S, Sobilo J, Lerondel S, Le Pape A, Pouvesle J-M. Response of human glioma u87 xenografted on mice to non thermal plasma treatment. Plasma Med. 2011;1(1):27-43.

19. Vandamme M, Robert E, Lerondel S, Sarron V, Ries D, Dozias S, Sobilo J, Gosset D, Kieda C, Legrain B, Pouvesle J-M, Pape AL. ROS implication in a new antitumor strategy based on non-thermal plasma. Int J Cancer. 2012;130(9):2185-94.

20. Köritzer J, Boxhammer V, Schäfer A, Shimizu T, Klämpfl TG, Li Y-F, Welz C, Schwenk-Zieger S, Morfill GE, Zimmermann JL, Schlegel J. Restoration of sensitivity in chemo-resistant glioma cells by cold atmospheric plasma. PLoS One. 2013;8(5):e64498.

21. Partecke LI, Evert K, Haugk J, Doering F, Normann L, Diedrich S, Weiss F-U, Evert M, Huebner NO, Guenther C, Heidecke CD, Kramer A, Bussiahn R, Weltmann K-D, Pati O, Bender C, von Bernstorff $\mathrm{W}$. Tissue tolerable plasma (ttp) induces apoptosis in pancreatic cancer cells in vitro and in vivo. BMC Cancer. 2012;12(1):1-10.

22. Siu A, Volotskova O, Cheng X, Khalsa SS, Bian K, Murad F, Keidar M, Sherman JH. Differential effects of cold atmospheric plasma in the treatment of malignant glioma. PLoS One. 2015;10(6):e0126313.

23. Cheng X, Sherman J, Murphy W, Ratovitski E, Canady J, Keidar M. The effect of tuning cold plasma composition on glioblastoma cell viability. PLoS One. 2014;9(5):e98652.

24. Kong MG, Kroesen G, Morfill G, Nosenko T, Shimizu T, Dijk Jv, Zimmermann JL. Plasma medicine: an introductory review. New J Phys. 2009;11(11):115012.

25. Ratovitski EA, Cheng X, Yan D, Sherman JH, Canady J, Trink B, Keidar M. Anti-cancer therapies of 21 st century: novel approach to treat human cancers using cold atmospheric plasma. Plasma Process Polym. 2014;11(12):1128-37.

26. Ishaq M, Bazaka K, Ostrikov K. Intracellular effects of atmospheric-pressure plasmas on melanoma cancer cells. Phys Plasmas. 2015;22(12):122003.

27. Ishaq M, Bazaka K, Ostrikov K. Pro-apoptotic NOXA is implicated in atmospheric-pressure plasmainduced melanoma cell death. J Phys D Appl Phys. 2015;48(46):464002. 
28. Tanaka H, Mizuno M, Ishikawa K, Nakamura K, Kajiyama H, Kano H, Kikkawa F, Hori M. Plasmaactivated medium selectively kills glioblastoma brain tumor cells by down-regulating a survival signaling molecule, akt kinase. Plasma Med. 2011;1(3-4):265-77.

29. Ishaq M, Evans MD, Ostrikov K. Atmospheric pressure gas plasma-induced colorectal cancer cell death is mediated by Nox2-ASK1 apoptosis pathways and oxidative stress is mitigated by Srx-Nrf2 anti-oxidant system. Biochim Biophys Acta. 2014;1843(12):2827-37.

30. Utsumi F, Kajiyama H, Nakamura K, Tanaka H, Mizuno M, Ishikawa K, Kondo H, Kano H, Hori M, Kikkawa F. Effect of indirect nonequilibrium atmospheric pressure plasma on anti-proliferative activity against chronic chemo-resistant ovarian cancer cells in vitro and in vivo. PLoS One. 2013;8(12):e81576.

31. Song K, Li G, Ma Y. A review on the selective apoptotic effect of nonthermal atmospheric-pressure plasma on cancer cells. Plasma Med. 2014;4(1-4):193-209.

32. Schlegel J, Köritzer J, Boxhammer V. Plasma in cancer treatment. Clin Plasma Med. 2013;1(2):2-7.

33. Barekzi N, Laroussi M. Effects of low temperature plasmas on cancer cells. Plasma Process Polym. 2013;10(12):1039-50.

34. Wang M, Yazici H, Gonzales A, Keidar M, Webster T. Selectively ablating malignant melanoma cell with combined therapy of cold atmospheric plasma (cap) and polymersomes loaded with protoporphyrin ix (ppix). FASEB J. 2015;29(1 Suppl).

35. Recek N, Cheng X, Keidar M, Cvelbar U, Vesel A, Mozetic M, Sherman J. Effect of cold plasma on glial cell morphology studied by atomic force microscopy. PLoS One. 2015;10(3):e0119111.

36. Bekeschus S, Kolata J, Winterbourn C, Kramer A, Turner R, Weltmann KD, Broker B, Masur K. Hydrogen peroxide: a central player in physical plasma-induced oxidative stress in human blood cells. Free Radic Res. 2014;48(5):542-9.

37. Wende K, Reuter S, von Woedtke T, Weltmann K-D, Masur K. Redox-based assay for assessment of biological impact of plasma treatment. Plasma Process Polym. 2014;11(7):655-63.

38. Weltmann KD, Kindel E, Brandenburg R, Meyer C, Bussiahn R, Wilke C, von Woedtke T. Atmospheric pressure plasma jet for medical therapy: plasma parameters and risk estimation. Contrib Plasma Phys. 2009;49(9):631-40.

39. Pipa AV, Ropcke J. Analysis of the mid-infrared spectrum of the exhaust gas from an atmospheric pressure plasma jet (appj) working with an argon\&\#x2013; air mixture. IEEE Trans Plasma Sci. 2009;37(6):1000-3.

40. Wende K, Williams P, Dalluge J, Van Gaens W, Aboubakr H, Bischof J, von Woedtke T, Goyal SM, Weltmann K-D, Bogaerts A, Masur K, Bruggeman PJ. Identification of the biologically active liquid chemistry induced by a nonthermal atmospheric pressure plasma jet. Biointerphases. 2015;10(2):029518.

41. Pipa AV, Reuter S, Foest R, Weltmann KD. Controlling the no production of an atmospheric pressure plasma jet. J Phys D Appl Phys. 2012;45(8):085201.

42. Kelly S, Gogna GS, Monaghan R, Daniels S, editors. Ozone mapping the kinpen-med plasma jet. 32nd International Conference on Phenomena in Ionized Gases, July 26-31, 2015, Iași, Romania

43. Reuter S, Winter J, Schmidt-Bleker A, Schroeder D, Lange H, Knake N, Gathen VS-vd, Weltmann KD. Atomic oxygen in a cold argon plasma jet: Talif spectroscopy in ambient air with modelling and measurements of ambient species diffusion. Plasma Sources Sci Technol. 2012;21(2):024005.

44. Daeschlein G, Scholz S, Lutze S, Arnold A, von Podewils S, Kiefer T, Tueting T, Hardt O, Haase H, Grisk O, Langner S, Ritter C, von Woedtke T, Jünger M. Comparison between cold plasma, electrochemotherapy and combined therapy in a melanoma mouse model. Exp Dermatol. 2013;22(9): $582-6$.

45. Law VJ, Cox LJ, Adress W, Graham WG, Dowling DP. Spatial and temporal imaging of a plasma jet plume. Chaotic Model Simulat. 2014;3:261-9.

46. Arndt S, Wacker E, Li Y-F, Shimizu T, Thomas HM, Morfill GE, Karrer S, Zimmermann JL, Bosserhoff A-K. Cold atmospheric plasma, a new strategy to induce senescence in melanoma cells. Exp Dermatol. 2013;22(4):284-9.

Volume 6, Issue 1, 2016 
47. Iannacone MR, Youlden DR, Baade PD, Aitken JF, Green AC. Melanoma incidence trends and survival in adolescents and young adults in queensland, australia. Int J Cancer. 2015;136(3):603--9.

48. Ishaq M, Kumar S, Varinli H, Han ZJ, Rider AE, Evans MD, Murphy AB, Ostrikov K. Atmospheric gas plasma-induced ros production activates tnf-ask1 pathway for the induction of melanoma cancer cell apoptosis. Mol Biol Cell. 2014;25(9):1523-31.

49. Georgescu N, Lupu AR. Tumoral and normal cells treatment with high-voltage pulsed cold atmospheric plasma jets. IEEE Trans Plasma Sci. 2010;38(8):1949-55.

50. Volotskova O, Hawley TS, Stepp MA, Keidar M. Targeting the cancer cell cycle by cold atmospheric plasma. Sci Rep. 2012;2:636.

51. Zucker SN, Zirnheld J, Bagati A, DiSanto TM, Des Soye B, Wawrzyniak JA, Etemadi K, Nikiforov M, Berezney R. Preferential induction of apoptotic cell death in melanoma cells as compared with normal keratinocytes using a non-thermal plasma torch. Cancer Biol Ther. 2012;13(13):1299-306.

52. Fridman G, Shereshevsky A, Jost M, Brooks A, Fridman A, Gutsol A, Vasilets V, Friedman G. Floating electrode dielectric barrier discharge plasma in air promoting apoptotic behavior in melanoma skin cancer cell lines. Plasma Chem Plasma Process. 2007;27(2):163-76.

53. Lee HJ, Shon CH, Kim YS, Kim S, Kim GC, Kong MG. Degradation of adhesion molecules of g361 melanoma cells by a non-thermal atmospheric pressure microplasma. New J Phys. 2009;11(11):115026.

54. Siret C, Terciolo C, Dobric A, Habib M-C, Germain S, Bonnier R, Lombardo D, Rigot V, Andre F. Interplay between cadherins and $\alpha 2 \beta 1$ integrin differentially regulates melanoma cell invasion. $\mathrm{Br} \mathrm{J}$ Cancer. 2015;113(10):1445-53.

55. Winograd-Katz SE, Fässler R, Geiger B, Legate KR. The integrin adhesome: from genes and proteins to human disease. Nat Rev Mol Cell Biol. 2014;15(4):273-88.

56. Zirnheld JL, Zucker SN, DiSanto TM, Berezney R, Etemadi K. Nonthermal plasma needle: development and targeting of melanoma cells. IEEE Trans Plasma Sci. 2010;38(4):948-52.

57. Yan X, Xiong Z, Zou F, Zhao S, Lu X, Yang G, He G, Ostrikov K. Plasma-induced death of hepg2 cancer cells: intracellular effects of reactive species. Plasma Process Polym. 2012;9(1):59-66.

58. Ahn HJ, Kim KI, Hoan NN, Kim CH, Moon E, Choi KS, Yang SS, Lee J-S. Targeting cancer cells with reactive oxygen and nitrogen species generated by atmospheric-pressure air plasma. PLoS One. 2014;9(1):e86173.

59. Kazuaki N, Tatsuo I, Masatoshi I, Takayuki Y, Hiroshi E, Kenji T, Yasunori T, Yoshihiko U, Nobuaki S. Evaluation of extra- and intracellular $\mathrm{OH}$ radical generation, cancer cell injury, and apoptosis induced by a non-thermal atmospheric-pressure plasma jet. J Phys D Appl Phys. 2013;46(42):425401.

60. Matthew JP, Hung-Wen C, Yukinori S, Douglas SC, David BG. Ozone correlates with antibacterial effects from indirect air dielectric barrier discharge treatment of water. JPhys D Appl Phys. 2013;46(14):145202.

61. Yan D, Talbot A, Nourmohammadi N, Cheng X, Canady J, Sherman J, Keidar M. Principles of using cold atmospheric plasma stimulated media for cancer treatment. Sci Rep. 2015;5:18339.

62. Szili EJ, Hong S-H, Short RD. On the effect of serum on the transport of reactive oxygen species across phospholipid membranes. Biointerphases. 2015;10(2):029511.

63. Moncada S, Erusalimsky JD. Does nitric oxide modulate mitochondrial energy generation and apoptosis? Nat Rev Mol Cell Biol. 2002;3(3):214-20.

64. Rauen U, Li T, Ioannidis I, de Groot H. Nitric oxide increases toxicity of hydrogen peroxide against rat liver endothelial cells and hepatocytes by inhibition of hydrogen peroxide degradation. Am Physiol Cell Physiol. 2007;292(4):C1440-9.

65. Asahi M, Fujii J, Suzuki K, Seo HG, Kuzuya T, Hori M, Tada M, Fujii S, Taniguchi N. Inactivation of glutathione peroxidase by nitric oxide: implication for cytotoxicity. J Biol Chem. 1995;270(36): 21035-9.

66. Vandamme M, Robert E, Pesnel S, Barbosa E, Dozias S, Sobilo J, Lerondel S, Le Pape A, Pouvesle J-M. Antitumor effect of plasma treatment on u87 glioma xenografts: preliminary results. Plasma Process Polym. 2010;7(3-4):264-73. 
67. Katharina S, Jan-Wilm L, Ines B, Julia Elisabeth B, Peter A. A H2 very high frequency capacitively coupled plasma inactivates glyceraldehyde 3-phosphate dehydrogenase(GapDH) more efficiently than UV photons and heat combined. J Phys D Appl Phys. 2014;47(8):085402.

68. Bazaka K, Jacob MV, Chrzanowski W, Ostrikov K. Anti-bacterial surfaces: natural agents, mechanisms of action, and plasma surface modification. RSC Adv. 2015;5(60):48739-59.

69. Ishaq M, Han ZJ, Kumar S, Evans MDM, Ostrikov K. Atmospheric-pressure plasma- and trail-induced apoptosis in TRAIL-resistant colorectal cancer cells. Plasma Process Polym. 2015;12(6):574-82.

Volume 6, Issue 1, 2016 